\title{
Repensando la agencia social de la mesocracia urbana en la relativa modernización de la Galicia rural: Ourense, $1880-1936$
}

\author{
RAÚl SOUTELO VÁZQUEZ ${ }^{*}$ \\ “Un historiador que no plantee problemas o que planteándolos no \\ formule hipótesis está más atrasado que el último de nuestros cam- \\ pesinos» 1
}

Desde una concepción transdisciplinar e integradora de las Ciencias Sociales, pretendemos reflexionar sobre el marco interpretativo construido por el equipo del profesor Villares frente a los planteamientos presentistas de Beiras Torrado, deudor de una conciencia de atraso surgida en la postguerra que se convierte en omnipresente deus ex máchina explicativo del subdesarrollo gallego actual, y sobre las acertadas percepciones de Pérez Touriño ${ }^{2}$ cuando revisa los clásicos de la literatura agraria marxista que han teorizado la inserción subordinada de las economias campesinas en sociedades globales de tipo capitalista y dotadas con superestructuras políticas de corte liberal burgués.

Facultade de Humanidades de Ourense.

El maestro LUCIEN FeVBre nos invita a un acercarnos empiricamente a las complejas realidades del mundo rural buscando una objetividad cientifica siempre condicionada por las fuentes y por la imposible imparcialidad del investigador en CC. Humanas. Cfr. FEvBRE, L. (1970): Combats pour l Histoire. Barcelona.

La presente aportación es una versión revisada de la comunicación aintelectuales y mesocracia urbana como determinantes e intérpretes de las transformaciones en el mundo rural ourensano. 1875-1936" que se presentó al 2.․ Congreso de la A.H.C. (Barcelona, 1992). Quisiera agradecer las enriquecedoras orientaciones de los profesores SANCHEz MARRoyo, Dominguez CASTRO y especialmente, de J.R. QUINTANA GARRIDO, siendo muy consciente de que aun no he resuelto todos los problemas que me han planteado.

2 Véanse sus reflexiones sobre las intepretaciones del problema agrario por la élite intelectual de Marxismo y del galleguismo de anteguerra in PÉREZ TOURIÑO, E. (1983): Agricultura y capitalismo. Análisis de la pequeña producción campesina. S.G.T. del M.A.P.A. Madrid.

(1984): "La cuestión campesina en Galicia" in E. SEVILLA GUZMÁN (coord.): Sobre agricultores y campesinos. Estudios de Sociología rural de España. Madrid, págs. 273-307. 
Por otra parte, queremos aplicar las potencialidades heurísticas del esquema construido por Pérez Ledesma ${ }^{3}$ al estudio de la acción colectiva y la movilización de recursos en la sociedad rural gallega (en transición a partir de la crisis agraria de los Ochenta), lo que exige prestar especial atención al origen social, los intereses de clase y los discursos regeneracionistas con que los empresarios políticos procedentes de la mesocracia intelectual y comercial urbana intermediaron la tardía y desigual modernización económica del mundo rural ourensano; supeditándola a un conflictivo proceso de cambio social que les convirtiese en nueva élite de poder en la (aún ruralizada) sociedad gallega de la Restauración. Coincidimos con el profesor Fernández Prieto en aseverar que "la comprensión del proceso histórico debe atender a los diferentes ámbitos de desarrollo de las dinámicas históricas, cuando menos desde una comprensión social y económica que se codeterminan de un modo complejo con las dinámicas definidas por el marco estatal' " ${ }^{4}$, pues la evidencia del recambio en la élite de poder de la Galicia rural de anteguerra, obliga a repensar en sentido crítico el excesivo optimismo con que se ha analizado el protagonismo del campesinado parcelario gallego en las transformaciones modernizadoras de sus explotaciones y al nivel de su adaptación forzada a las imposiciones de un mundo urbano y capitalista en expansión. En la economia campesiña gallega del cambio de centuria, las estrategias familiares de producción económica y socialización (condicionadas al objetivo prioritario de su reproducción social maximizando los escasos recursos a su alcance) ${ }^{5}$ se codeterminan en las es-

\footnotetext{
3 Pérez ledesma, M. (1994): "Cuando lleguen los dias de la cólera (movimientos sociales, teoria e historia)" in Problemas actuales de Historia. Terceras Jornadas de Estudios Historicos. Salamanca. Para una aguda reftexión sobre la construcción de los imaginarios politicos de los agregados populares y la modernización de sus formas de protesta a través de luchas proactivas, cfr. Perez Ledesma, M. (1992): El obrero consciente. Dirigentes, partidos y sindicatos en la Segunda Internacional. Madrid. Alianza Universidad.

4 Foez. Prieto, L. (1993): "Represión franquista y desarticulación social en Galicia. La destrucción de la organización societaria campesina. 1936-1942" in Historia Social, n." 15, págs. 4965. Valencia. Cfr. pág. 49.

A propósito del papel intermediario de agentes sociales individuales o colectivos que interpelaron al campesinado agrarista con la finalidad última de hegemonizarle en lo organizativo y representarle a nivel comicial cfr:

Hervés Sayar, H. (1987): Agrarismo e politica na comarca do Condado. 1900-1936. Tesis de Licenciatura defendida en la Universidad de Santiago de Compostela.

(1993): "A propósito del conflicto antiforal en la Galicia del primer tercio del s. Xx. Asociacionismo agrario y resistencia campesinan in Áreas, 15. Murcia, págs. 55-73.

SOUTElo VAzQUEZ, R. (1994): A burguesia intelectual e as transformacións no mundo rural en Galicia: Ourense, 1880-19.36. Tesis de licenciatura defendida en la Facultad de Humanidades de Ourense y dirigida por el profesor D. Jesus de Juana, cuya magistral orientación científica y constante apoyo personal queremos agradecer aqui.

Para una interesante revisión de los caracteres del campesinado y sus formas de pluriactividad económica cir.: Dominguez Martin, R. (1993a): "Caracterizando al campesinado y la eco-
} 
feras de lo económico y sociopolítico con el subordinante papel de abastecedores de productos y "motores de sangre" impuesto por agentes aliados del capitalismo urbano y de la élite de poder del Estado Liberal español. Por otra parte, debemos considerar el carácter parcial de una sociedad rural gallega que si bien en lo económico evoluciona hacia modelos de explotaciones familiares plenamente individualizadas en lo que a la gestión y a la propiedad de los recursos se refiere (especializándose en la producción de carne y vino para mercados urbanos), en sus redes relacionales siguen teniendo plena vigencia los espacios y formas de sociabilidad comunitaria, y la negociación de "political midlemens" (Basilio Alvarez y el nucleo de intelectuales dirigentes de Acción gallega en Ourense, Amado Garra en O Condado o Pita Romero en Ortegal) con los órganos estatales de la sociedad global. Estos serán quienes incentiven la actuación política de facciones de clase media urbanas para controlar esferas de poder como empresarios políticos que hegemonizan la acción colectiva de un campesinado parcelario al que utilizan como masa de maniobra electoral para romper el monopolio político de la vieja élite turnista hasta $1923^{\circ}$. Agentes sociales procedentes de la pequeña burguesia intelectual pilotarán el proceso modernizador de las estrategias tradicionales de resistencia campesina - motines y violentas “jacqueries» contra los agentes de la injusta sobreexplotación por el Estado Liberal y los propietarios rentistas desde su monopolio de las instituciones locales-, organizándoles en sociedades agrarias con la mediación de lideres semicampesinos locales, pero que han sido socializados previamente en las formas conflictuales de reivindicación en experiencias migratorias o de proletarización urbana. Serán pués las relaciones externas de los individuos y sectores más

nomia campesina: pluriactividad y dependencia del mercado como nuevos atributos de la "campesinidad", in Agricultura y Sociedad, 66. Madrid, págs. 97-136.

(1993b): "Sociedad rural y campesinado en la cantábria decimonónica" in M. SUAREz CORTINA (ed.): El perfil de la Montaña. Economia, Sociedad y Politica en la Cantabria contemporánea. Santander, 1993.

(1995): "Campesinos racionales con estrategias adaptativas" in A. MONTESINo GLEz. (ed.): Estudios sobre la sociedad tradicional cántabra. Continuidades, cambios y procesos adaptativos. Santander, págs. 157-179.

- Cfr. WoRSLey, P. (1984): "Economias campesinas" in R. SAmuel (ed): Historia popular y teoria socialista. Barcelona. Critica. En especial pág. 171. Planteamiento compartido por el profesor Sanchez Marroyo, F. (1979): Sindicalismo agrario y movimiento obrero. Caceres, 1906-1920.

(1994): "Violencia campesina, impotencia pequeño burguesa y reacción conservadora: el Sexenio democrático en Extremadura" in Anales de Historia Contemporánea, 10. Págs. 540-556.

Sobre los esfuerzos de los propietarios agrarios para crear un societarismo católico desde for mulaciones neotradicionalistas que garantizasen su permanencia como élite local en el mundo rural cfr. Montero Garcia F. (1992): “El movimiento católico en España: la respuesta de la provincia eclesiástica de Valladolid a la encuesta Vico (1908)" in Espacio, Tiempo y Forma, s. V, t. V, Madrid, págs. 342-366. 
dinámicos (=adaptativos) del campesinado, el elemento determinante para la modernización de las comunidades rurales, subordinadas a los intermediarios políticos y económicos de la sociedad global.

La observación empírica en las tierras cerealeras del noroeste ourensano nos han permitido comprobar que la dirección socio-política del campesinado agrarista únicamente fue ejercida a nivel local por agentes de su status: líderes semicampesinos que habian sido socializados en espacios urbanos gallegos o ultramarinos, en las modernas formas de conflicto y/o pacto social. La acción colectiva del campesinado parcelario gallego en Política será instrumentalizada "desde fuera", por una alianza táctica entre desiguales con los nucleos dirigentes de las formaciones políticas obreristas y de clase media críticas con el sistema de reparto del Poder de la Restauración. En este proceso conflictual de reivindicación, los sectores más dinámicos del campesinado gallego contruyeron una autopercepción de "clase para sí», acorde con lo aseverado por Quintana Garrido a tenor de la participación campesina en las revoluciones contemporáneas ${ }^{7}$.

La experiencia de migración ultramarina o proletarización urbana le permitió al campesino parcelario gallego (a nivel familiar como colectivo) dotarse de una capacidad de respuesta adaptativa que pasaba por la puriactividad económica ante las nuevas condiciones capitalistas de [re]producción económica y social (maximizando con suplementaria mano de obra femenina e infantil, los recursos de la explotación que se maquiniza y especializa) y por la inserción política (permitida por la Ley de Asociaciones de 1887 y el sufragio universal masculino de 1890) desde las multiformes facciones agraristas caracterizadas por un común reformismo agro-populista que oscilaba desde el paternalismo socialcatólico al demagógico mesianismo de Basilio Alvarez. Fernández Prieto ha demostrado que las transformaciones capitalistas en las formas de explotación campesina no pueden aprehenderse en clave exclusivamente económica o técnica - priorizando la importancia cualitativa de la introducción de insumos de procedencia científico-industrial y propuestas tecno-productivistas aportadas por la intelectualidad urbanapor tratarse de un proceso a la par social y político mediatizado por la acción de unas élites de poder estatal para modernizar las formas de propiedad y explotación manteniendo el orden social, garantizando la propiedad privada y la hegemonía política de sus agentes sociales en la Galicia rural ${ }^{8}$.

\footnotetext{
Cir.: Quintana Garaido, X.R. (1993): "Movemento obreiro, Socialismo e Historia Social" in A Trabe de Ouro, 14, págs. 247-255. Santiago. En especial pág. 251.

(1991): "Campesinos que se adaptan y agricultura que se mueve. De la Historia agraria de la Galicia contemporánea" in Areas, 12. Murcia.

- Fernandez Prieto, L. (1992): Labregos con ciencia. Estado, sociedade e imnovación tecnolóxica na agricultura galega. 1850-1939. Xerais. Vigo. Cfr. págs. 161 e 459-463.
} 
En este escenario social, los campesinos gallegos aceptaron una alianza de rendimiento desigual con los dirigentes socialistas del esclerótico obrerismo y con las facciones reformistas de la pequeña burguesia urbana para romper el monopolio local que ejercian los propietarios y rentistas utilizando los recursos de la administración política y judicial para garantizar la reproducción de sus patrimonios y clientelas electorales entre un campesinado económicamente subordinado y dominado en su representación y participación en las esferas del poder. Realidad que los profesores Landsberger y Casanova han señalado partiendo de la común percepción de que en cualquier proceso de acción colectiva y movilización de recursos "las ideas nunca son sólo fuerzas independientes ni expresiones mecánicas de intereses materiales, ya que la conciencia une los intereses a la acción a través de procesos históricos que necesitan ser investigados en cada caso" ". El campesinado gallego fué capaz de dotarse de una "vanguardia" agrarista propia que dirigiera su acción colectiva a nivel local pero cuanto más extenso, nacional y permanente llegó a ser este movimiento campesino, menor fué la probabilidad de que se mantuviese su dirección en el propio campesinado, siendo cada vez menos los líderes de un nivel supralocales socializados en familias campesinas de estatus bajo.

\section{LAS ESTRATEGIAS E INTERPELACIONES DE LA MESOCRACIA INTELECTUAL OURENSANA PARA INTERMEDIAR LA MOVILIZACIÓN COLECTIVA DEL CAMPESINADO DURANTE LA RESTAURACIÓN}

Los tratadistas gallegos de la problemática foral, que mayoritariamente percibian ingresos por foros o aparcerias y contaban con otra renta fija por su dedicación al funcionariado estatal, serán interesados interpretes del proceso histórico de adaptación y/o subordinación de las explotaciones familiares domésticas a las demandas del mercado capitalista ${ }^{10}$ español. Circunstancia

Sobre la intermediación política en la Galicia rural cfr. CARDESín DiAZ, J. M. (1993a): Ricos labradores, caseiros y camareiras: transformaciones económicas y juridico políticas en una aldea de Galicia" in Ler Historia, 23. Portugal, págs. 79-99; y LaGo PENAS, P. (1993b): "Repensando el caciquismo: espacio politico y agencia social en la Galicia de la Restauracion" in Historia y Critica, 2. Santiago de Compostela, págs. 191-226.

- Cfr.: Casanova, J. (1991): La historia Social y los historiadores. Barcelona. Critica. En especial pág. 107. LANDSBERGEA, H. (ed.) (1978): Rebelión campesina y cambio sociai. Barcelona. Crítica. Véanse págs. $8,71-74$ y 77.

10 Sobre la caracterización como comercio forzado de la inserción subordinada de la pequeña producción campesina en los circuitos comerciales del capitalismo por la necesidad de monetarizar el excedente para entrentarse a la creciente tributación impuesta por el estado Liberal, véase el ya clásico BHAduRI, A. (1987): La estructura económica de la agricultura atrasada. F.C.E. 
que explica que los agentes políticos de los foristas instalados en el partido conservador (Díaz de Rábago, García Ramos, Camarasa, Besada o Bugallal) defiendan el impasse acordado en el Congreso Agrícola de $1864^{11}$.

Mientras que Montero Ríos y su yerno E. Vincenti, actuando como modernos empresarios políticos que hegemonizan con su liderazgo las lealtades personales de los agentes locales que controlan las redes clientelares del Partido Liberal, defienden en el Proyecto de Redención de Foros y Censos de 1886, la unificación del dominio en manos del cultivador directo como condición indispensable para la necesaria modernización técnico-productivista de la agricultura gallega. Cuando el marqués de Camarasa, adalid de los foristas opuestos a la redención desde el baluarte conservador, les tilda de socialistas, Vicenti replica al portavoz de los "parásitos de la propiedad" que ellos como liberales sólo aspiran a que "el trabajador rural no sucumba, la propiedad pueda desarrollarse y se impulse el progreso agricola sin despojar a nadie de su propiedad" 12 . Planteamiento coincidente con las interpelaciones que realizan al elector labriego las facciones republicana (Paz Novoa con la efímera pero cualitativamente importante Ley de Redención de 1873) ${ }^{13}$ y demócrata de las emergentes clases medias urbanas, anhelantes de un campesiñado pequeño propietario con capacidad de ahorro que le libere de la dependencia económica y social de prestamistas de dinero o ganado y sirva de freno a la expansión del Socialismo en el medio rural, anatematizado agente de la convulsión social denunciada por cuantos eruditos se preocuparon del problema ${ }^{14}$.

México. La mercantilización como respuesta adaptativa del campesinado están analizadas por $R$. Dominguez MARTin (1993b y 1995).

1 Cir. DuRAN, J.A.(1977): Agrarismo y movilización campesina en el pais gallego (1875-1912). Madrid, pág. 11.

Item VILLARES PAZ, R. (1983): “Els foros de Galicia. Uns quants problemes i comparacións» in Estudis D'Historia Agrària, 7. Barcelona, págs. 161-185.

12 Cfr. VICENTI, E. (1888): La propiedad territorial en Galicia. Polémica relativa al proyecto de ley de Rendención de censos y foros del ex-Ministro de Fomento Sr. Montero Rios. A Coruña.

13 Ministro durante la Primera República, sus planteamientos transformadores de la propiedad fundiaria pueden verse in PAZ NovA, J. M. (1872): Los foros en Galicia. Apuntes sobre la actual organización de la propiedad territorial en estas cuatro provincias y necesidad de su reforma. Imprenta La Popular. Ourense. Sobre la incidencia redentora de esta lei cfr. Lopez RGUEz., P. (1985): Campesinos propietarios. La redención de foros en la provincia de Lugo durante la Primera República. Lugo.

14 La aseveración del profesor BARREIRO FERNANDEZ, X.R. (1992): A Sociedade Galega Contemporánea. Historia de Galicia: vol. V. A Coruña, pág. 254, queda validada en las obras de:

VILLAAMIL y CASTRO (1883): Origen de los foros en Galicia. Madrid.

CAStROVIEJO, A. (1910): La asociación agrana socialista y acrata. Santiago.

ROMERO MOLEZUM, C. (1902): Observaciones acerca de los foros temporales. Santiago.

MON LANDA (1910): Estudio de los foros. Madrid.

Martinez SueIRo, M. (1912): La cuestión agraria en Galicia. Redención de foros y subforos: una solución equitativa. Ourense. 
En la agrociudad ourensana finisecular, el regionalista conservador Lamas Carvajal representa desde O Tio Marcos da Portela una corriente laudatoria del campesino rico ${ }^{15} \mathrm{o}$ labrador alfabetizado, poseedor de tierras y ganados explotados directamente ou en aparcería. Víctima de la rapiña del Estado y necesario agente dinamizador de un societarismo modernizador de las explotaciones pero con orden social y ajeno a planteamientos redencionistas. Casado con una dama rentista del Ribeiro, la obra del juez de instrucción Gumersindo Buján, evidencia hasta que punto los intereses de clase mediatizaban el discurso de esta mesocracia intelectual que aspiraba a controlar espacios de poder:

"El redencionismo ni me satisface ni me convence, por no ser licito ni justo el procedimiento que proponen los pagadores para liberar la propiedad e la carga foral. Se me antoja ineficaz y contraproducente a los intereses de la producción rural. Entiendo que perdurará el foro como beneflcioso gravamen perpetuo sobre la propiedad de la tierra" "

Sin perjuicio de ser el vigésimo tercer perceptor de rentas forales entre los 329 perceptores del Ribeiro, su bohemio hijo Antonio Buján Pérez presidirá la Sociedad de Agricultores de Ribadavia durante las campañas basilistas de 1913 a 1916 y organiza en 1921 la Federación Provincial de Sociedades Agrícolas con el objetivo de conseguir "la total emancipación de la clase trabajadora campesina, y cuando las circunstancias lo aconsejen la inmediata socialización de la tierra" " ${ }^{17}$. Consideramos que este discurso, modernizador del agro y aparentemente liberador de los labriegos tal como Luis Dominguez a puesto de manifiesto, esconde una estrategia de permanencia en la cúspide social abrazando la demagogia populista del cura de Beiro. Seria una reedición fidalga de la gatopardesca estrategia de "cambiarlo todo para que nada cambie" ${ }^{18}$ más allá de sus intereses colectivos. En principio, los componentes de este agregado

15 Para un acercamiento interdisciplinar a la diferenciación interna del campesinado gallego y las redes clientelares como condicionante de su reproducción social cfr. CARDESiN, J.M. (1993a), argumentación desarrollada en su excelente tesis (1992): Tierra, trabajo y reproducción social en una aldea de Galicia. Muerte de unos, vida de otros. S.G.T. del M.A.P.A. Madrid.

1is Bujan Noguerol, G. (1902): De la propiedad y los foros. Estudio juridico social. Imprenta de A. Otero, Orense, Ctr. p. Vill.

17 Extraido del Reglamento de la Federación Provincial de Sociedades Agricolas. 1-VI-1920.

is Nos referimos a la justificación del joven Tancredi a su principesco tio ante su roja camisa garibaldina en los dias del desembarco en Nápoles. Las obras de G.T. LAMPEDUSA El gatopardo y Otero Peoralo, R. (1990): Os camiños da vida, constituyen una inapreciable fuente literaria para el estudio de los espacios y formas de sociabilidad pública y privada en los grupos procedentes de Antiguo Régimen, así como de sus mecanismos de adaptación a la nueva sociedad urbano liberal con una economia de mercado. 
social de profesionales liberales y comerciantes con intereses agrarios menosprecian a los emergentes nucleos societarios del hinterland urbano, pero la presencia de obreros semicampesinos que difunden desde las directivas agrarias un imaginario político de corte socialista les impulsará a reflexionar sobre lo que ya perciben como problema agrario, interpelando al colectivo con el que se identifican en términos de clase ante la expansión de "deologias disolventes del orden social" en el agro:

"La agitación prerrevolucionaria de nuestras aldeas por la redención de foros es fantasia fuera de la tónica general... El movimiento rural gallego es en gran parte de elaboración doctrinal artificiosa y se ahoga en cuanto los agitadores viven a distancia de Galicia... Un centenar de sociedades agricolas se organizaron en lo que va de siglo; la tercera parte de procedencia roja, casi otra tercera de origen social-católico y el resto, a modo de máquinas de guerra contra el caciquismo, manejadas de ordinario por caciques que aspiran al poder municipal’" ${ }^{19}$.

El sesudo notario de Carballiño, percibe los intereses ocultos en las sucesivas facciones que intentaron hegemonizar la acción colectiva y los sufragios de la población rural: solidarios, antiforistas y ahora, el núcleo basilista de Acción gallega, pretenden erigirse en nueva élite de poder como representantes de un campesinado manipulable como masa de maniobra electoral por los agentes locales del Turno y por los empresarios políticos que aspiran a relevarles en el usufructo de los diversos espacios del Poder:

"En el alma gallega de las ciudades y los campos se esconden grandes energias transformadoras y esta cuestión de los foros, recibiendo el aliento de millares de gallegos de América comienza a apasionar fuertemente los ánimos Lo que no ocurrió hasta ahora podria acontecer pronto si la propaganda se espesa algo más y continua actuando sobre el inconsciente bloque de nuestros campesinos como al parecer actuó hace años en algunos lugares la hidra de la rebeldía socialista y del anarquismo" 20.

Paralelamente, la segunda década del siglo contempla en la Galicia rural el esfuerzo transformador de las explotaciones agropecuarias desde proyectos técno-productivistas desarrollados y difundidos en la prensa de la época por técnicos como Rof Codina, Cruz Gallastegui o Javier Prado "Lameiro" ${ }^{21}$ y la paralela movilización proactiva del campesinado en los

19 Cir. Martinez Sueiro $(1912,1)$.

20 Martinez Sueiro $(1912,2)$.

21 Véase al respecto Rof CODINA, J. ([1912] 1966): “reformas que se pueden implantar en Galicia para el progreso de la agricultura" in Revista de Economia de Galicia, n. ${ }^{\circ} 55$. Vigo, págs. 79-90. 
reivindicativos mítines de Acción Gallega. Inicialmente, la presencia de Basilio Alvarez - sacerdote formado en el recio activismo socialcatólico ourensano de los obispos Carrascosa e Ylundain ${ }^{22}$ dirigiendo el conglomerado agro-populista y regionalista de Acción Gallega- tranquitizaba a los notables civiles y eclesiásticos locales y fueron muchos los párrocos que animaron a sus feligreses a organizar sindicatos agrícolas para la adquisición cooperativa de insumos. Pero desde mediados de 1914, la progresiva radicalización de la demagógica retórica del cura de Beiro y la disidencia de miembros del nucleo dirigente del movimiento le restarán credibilidad entre la mesocracia urbana. Además, la muerte de Canalejas que esperaba utilizar políticamente a la facción basilista para romper el caciquismo turnista en Galicia, permite a la élite política local usar todos los recursos coactivos de la administración (embargos por impagos de rentas con la Guardia Civil, exacciones impositivas, etc.) contra los agrarios. Siguiendo el ejemplo irlandés, Basilio Alvarez viaja a Cuba y Argentina buscando el apoyo económico y la legitimación galleguista de la parroquia de acolá; al regresar el movimiento está roto pero sus incendiarios discursos le han convertido en hiperindividuo hegemónico en el imaginario colectivo de unas comunidades campesinas asombradas cuando un cura ensotanado les invitaba a ejercer las mas violentas [pero también efectivas] formas de lucha reactiva:

"El pueblo gallego ha sido llevado al Gólgota y clavado en una cruz, el cacique lo injuria con sarcasmos... iAlzáos, levantad vuestros puños, precipitad a los ladrones en los barrancos, asaltad sus haciendas que os fueron robadas a vosotros, sus casas que tienen en cada sillar pedazos de vuestras vidas y poned un punto de tragedia horrenda a tanto oprobio!'”23.

Fracasado como valladar a la hegemonía socialista en las sociedades agrarias el populismo regionalista de Acción Gallega, propietarios y párrocos organizan desde 1916 un potente sindicalismo católico en las zonas vitícolas y en las penillanuras de policultivo y ganado del N.O. de Ourense. En 1924 había 38 entidades socialcatólicas dirigidas por propietarios (35\%), profesionales liberales $(23 \%)$, sacerdotes $(13 \%)$ e industriales o comerciantes $(10,3 \%){ }^{24} \mathrm{IO}$

22 Sobre este aspecto ha trabajado DE JUANA LOPEZ, J. (1986): "As orixes do sindicalismo católico en Ourense: fundación e organización do Circulo Católico de obreiros" in X. CASTRO PÉREz E J. DE JuANA (eds.): III Xornadas de Historia de Galicia. Ourense, págs. 257-320.

2.3 Extraido del mitín de Basilio Álvarez en padrenda (Ourense, 16-X1913), recogido por el hagiográfo Montero Mejuto, J. (1915): Valores nuevos de la Politica. Basilio Alvarez y los agrarios gallegos Madrid. Pág. 57.

24 Tomamos los datos de Martinez López, A. (1991): O cooperativismo católico no proceso de modernizacion de agricultura galega. Pontevedra. 
que confirma la agencia social de individuos hacia los cuales la comunidad tenía unas relaciones de obligación materiales o imaginarias, para movilizarles a una acción colectiva no atentatoria contra el orden socio-político de la Restauración:

"Los vecinos acordaron formar una sociedad agricola católica mútua, con el fin de oponer resistencia a las doctrinas antinaturales $y$ deletéreas que determinados elementos pretenden introducir en el ayuntamiento y a mismo tiempo, para la consecucion de otros fines instructivos y económicos bajo la dirección del que suscribe» 25 .

Una década de estudios de Historia social rural en Galicia nos permiten conferir una mayor importancia a las estrategias reales y programas aparentes de los empresarios politicos de clase media que participan en la movilización proactiva de los recursos asociativos del campesinado con fines comerciales y de intermediación política ante las transformaciones impuestas por la sociedad global a partir del cambio de centuria según se recoge en las brillantes sintexis realizadas por la escuela de Villares ${ }^{26}$. López Taboada ha puntualizado con acierto que "con la crisis agraria finisecular cae el valor de mercado de las rentas en especie devaluandose la tierra... Paralelamente a esta perdida de la hegemonia económico social de la fidalguia en la Restauración aumenta la concienciación y la iniciativa del campesinado que en los procesos migratorios transoceánicos y urbanizadores mejoró sú posición negociadora en el debate de acceso a la propiedad y en

Sobre las forzadas readaptaciones programáticas de los empresarios politicos socialistas para interpelar a los agregados rurales véase:

Biglino CAMPOS, P. (1986): El Socialismo español y la cuestión agraria. 1890-1936. Madrid

Gonzalez Probados, M. (1992): "A acción agraria socialista na Segunda República" in D. PEREIRA (coord.): os conquistadores modernos. Movemento obreiro na Galicia de anteguerra. Eds. A Nosa Terra. Vigo, págs. 173-194.

2: Carta del sacerdote C. RuAS Gonzalez al obispo de Ourense, presentándole los Estatutos de la Sociedad Católica Amor y Justicia de Amoeiro (22 de junio de 1914) in Arquivo Diocesano de Oruense, carpeta 4.3.3. Al nivel actual de nuestros conocimientos, la comarca vitivinicola del Ribeiro y las tierras cerealeras del Noroeste oruensano presentan claros ejemplos de pluriactividad campesina, fruto nacional de la inserción de las explotaciones domésticas en el mercado y por el potente abolicionismo del Sur de Lugo y del Bajo Miño como hemos demostrado in SOUTELo VAZQUEZ, R. (1995): "Algúns aspectos do movemento agrarista nos concello de Amoeiro, 19101936" in J. DE JuAna e X. CAStro (eds.): Aspectos históricos de Ourense. Anexo a las VIII Xornadas de Historia de Galicia. Ourense, págs. 223-236.

26 Cir. Herves Sayar (1993) y Quintana Garrido (1991). Item Artiaga Rego, A. y Baz Vicente M." J. (1993): "Os estudios de H." agraria en Galicia: balance dunha década" in Beramend (ed.): Galicia e a Historiografia. Tórculo Eds. Santiago de Compostela, págs. 275-302.

FERNANDEZ PRIETO, L. (1994): “Transformacións agràries i canvi social en la Galicia rural contemporània" in Estudis D'Historia Agrària, 10, págs. 5, 25. 
la incorporación al mercado de imputs y ouputs, introduciendo mejoras tecnológicas para aumentar los niveles de productividad y capacidad de consumo" ${ }^{27}$. Entretanto la antigua clase rendista liquida sus propiedades rurales y cambia el capital liberado a otros sectores productivos, o se ahoga lentamente en gastos no reproductivos, perdiendo su hegemonía económico-social. Los propietarios rentistas aprovechan la garantia de orden social de la primera dictadura para deshacerse por via redencionista de unos devaluados patrimonios forales ante la amenaza abolicionista de los cultivadores ${ }^{28}$. En el esquema clásico de Villares, la Ley de Redención de Foros (25-VI-1926) ratifica formalmente la via prusiana de aparición en el conglomerado social del rural gallego del campesinado parcelario cuando ya le es inutil la plena propiedad de una tierra cuya posesión habia constituido el objetivo prioritario de sus estrategias de reproducción social desde la temprana Modernidad ${ }^{29}$.

La caida de las rentas forales con la crisis de los ochenta y la ulterior asimilación de los sectores mas dinámicos del bloque rentista en las nuevas élites de poder urbano-capitalista, suponen factores de quiebra que favorecen la movilización de recursos proactivos desarrollada por los diversos proyectos agraristas en una coyuntura económica propicia para la inserción de las explotaciones familiares campesinas en los mercados de factores de producción (capital humano emigrado) y mercancías. Con ello concluye la multisecular detracción foral del excedente agrario, limitando la capacidad de aforro campesino sin que el bloque rentista haya actuado [en cuanto colectivo] como "agricultor a la moderna" que invirtiese su capacidad y dinero en la modernización de las estructuras de propiedad y explo-

a7 Cfr. Lopez TABOAdA, X.A. (1992): "Notas para a contribución a un debate sobre a movilidade dos factores de produccion agraria: seculo $X \mathrm{IX}$ e primeiro tercio do XX" in Fevista Galega de Economia, n. 1. Santiago de Compostela, págs. 49-58.

${ }_{28}$ El aprendizaje de nuevas formas proactivas de protesta social y la confianza en la presión reactiva que ejercia la comunidad parroquial, permitieron a las familias campesinas optar por la inversión racional de las remesas migratorias en adquirir tierras y ganados o mejorar el equipamiento de las explotaciones, frente a la posibilidad real de redimir las tierras sujetas a foro ya que la mivilización posterior a 1917 apuntaba a una solución revolucionaria que sólo en la Dictadura pudieron contener los propietarios rentistas. Cfr. BERnALdo DE Quiros y RIVERA PASTOF (1923): El problemas de los foros en el N-O. de España. Madrid. En especial págs. 82-83.

2: Este planteamiento, debido al profesor Villares, corregiria su optimismo inicial respeto de una derrota del rentista ante el empuje agrario. Los posteriores trabajos de Luis Domínguez insinuan por el contrario una estrategia de pactar redenciones e desactivar la potencia revolucionaria de las sociedades agrarias negociando con sus lideres locales. Cfr. VhlaRES PAZ, R. (1982): Foros, frades e fidalgos. Estudios de Historia Social de Galicia. En especial pág. 236. Una comparación con la enfiteusis de los paises catalanes y los prazos portugueses cfr. VILLARES, R. (198.3), para una revisión general véase también VILLARES, R. (1991): "La agricultura gallega contemporanea (1850-1936), permanencias y cambios" in Áreas, 12. Murcia. 
tación agrarias en la Galicia rural contemporánea. Ulteriores investigaciones en los archivos pacegos, complementadas con el recurso a la memoria oral de señores y aparceros para una reconstrucción pormenorizada de las estrategias económicas de las entidades perceptoras ourensanos, demuestran que parte de los foros nunca se redimieron, extinguiéndose por consunción, y que la favorable coyuntura de precios agrarios en alza y mano de obra barata en la rerruralizante postguerra impulsan a los propietarios a asumir de nuevo la gestión directa de sus patrimonios hasta la desestructuración del mundo rural por las riadas migratorias de los años sesenta ${ }^{30}$.

La burguesía comercial e intelectual urbana coincidía por contra, en la necesidad estratégica de una transformación técnico-productivista de la pequeña producción campesina que convirtiese al labriego en demandante de imputs industriales y en reserva electoral para sus proyectos de reforma del inoperante y excluyente Turno dinástico. La adaptación de la explotación doméstica a la sociedad global capitalista pasaba necesariamente por la campesinización de la propiedad como vía de desarrollo del capitalismo en la agricultura, frente a la alternativa de remodelación de las explotaciones con criterios de concentración racionalizadora que permitiese una explotación maquinizada típicamente capitalista. La burguesía intelectual y comercial urbana potencia la auto-organización societaria de los individuos más dinámicos en las comunidades campesinas, orientándoles programáticamente y en su acción colectiva como mecanismo de intermediación proactiva para convertirseles económicamente en agricultores insertos en el mercado. Sin embargo, en sus imaginarios colectivos y redes de sociabilidad continuarán subordinados a los tradicionales espacios de familia y comunidad.

La orientación prioritariamente antiforal y de lucha políica anticaciquil del agrarismo ourensano, frente al caracter desarrollista de las asociaciones de la Galicia septentrional - volcadas en la comercialización cooperativa y la especialización ganadero-pratense-, puede estar en relación con la tradicional fortaleza y capacidad de resistencia de la comunidad campesina en la Galicia interior apuntada por Villares (1983:174-175) y sus colaboradores ${ }^{31}$.

\footnotetext{
30 La gestión directa del patrimonio parece haber sido la tónica dominante en el Ribeiro y en las casas solariegas de las tierras cerealeras del noroeste de Ourense según se desprende del estudio de Luis Dominguez para los Pardo de Casaldereito y de las informaciones de D. Elias Rivas Martinez, dueño del Coto Martín de Bóveda y varios caseros de los pazos de S. Damián y a Martinga, todos ellos en Amoeiro. Cfr. Soutelo Vazouez, R. (1995) e Dominguez Castro, L. (1992): Viños, viñas e xentes do Ribeiro. Economia e patrimonio familiar, 1810-1952. Vigo.

3 Cir.: Fernández Prieto, L. et alii (1995): "Resistencia y protesta. Una visión a largo plazo de la conflictividadrural en la galicia contemporánea" in Actas VII Congreso de Historia Agraria. Baeza, págs. 89-99. En especial págs. 91 y 96.
} 
En el debate sobre el alcance y los aspectos de los procesos adaptativos por los cuales individuos y grupos campesinos intentan controlar sus relaciones con el mercado para garantizar la reproducción de sus unidades domésticas - codeterminada por sus relaciones de propiedad y explotación con la tierra-, es necesario superar el monogámico idilio con la acertada categoría de "adaptación» como referente exclusivo para los agregados populares de la sociedad rural. La investigación microhistórica corrobora las aseveraciones de Fernández Prieto (1994) y Cardesín (1992) sobre el protagonismo esencial del campesino medio y acomodado (los ricos y labradores estudiados por el segundo) ${ }^{32}$ en la dirección ideológica y organizativa de la movilización de recursos políticos en la Galicia rural. En este sentido, hemos constatado los esfuerzos de transformación agropecuaria y vitícola de la pequeña y mediana producción campesina en el hinterland rural de Ourense o en áreas de fuerte emigración (Vilamarín, o Ribeiro), experiencia que familiariza al campesino proletarizado con una mínima formación agronómica y con formas proactivas de reivindicación político-social. Venciendo la resistencia [más tópica que real] del campesino a todo proceso de cambio externo a su control, emigrantes, obreros y burgueses intelectuales interpelan con discursos regeneracionistas o socialistas a los sectores más afectados por la adaptación al mercado, dinamizando un proceso de construcción del campesinado gallego como clase que evidencia la notable presencia de propietarios y profesionales liberales en las directivas agrarias ${ }^{33}$. En alianza subordinada con ellos, el campesino medio y acomodado accede al control de la administración judicial y

VELASCO SOUTO, C.F. (1995): "Estrategias campesinas en la lucha por la tierra. Galicia, 18001868. Algunos datos e interrogantes in Actas... págs. 101-112.

${ }_{32}$ Seria este sector de labradores ricos, con ganado y tierras propias dedicados al "trato" ganadero en los circuitos de ferias y al préstamo de dinero con usura, quienes establecen tiendas de ultr5amarinos en las que los labriegos compran a fiado, entrando en unas relaciones de obligación que tendrán contraprestaciones de trabajo y fidelidad electoral determinantes para la asimilación de aquellos a la elite local que intermedia los procesos electoraes e intenta neutralizar la subversión social de las agrarias parroquiales. Proceso que hemos constatado empiricamente en Amoeiro e Vilamarin: labradores-comerciantes entran en la politica local como representantes agrarios aliados a una de las familias liberales y en 1923 se convierten en notables locales de la Unión Patriótica.

33 Sobre el papel orientador y rector de los indianos en ia creación de un nuevo imaginario politico y la movilización de recursos proactivos del campesinado gallego de anteguerra cfr.:

NUNEEZ SEIXAS, X.M. (1994): "Las remesas invisibles. Algunas notas sobre la influencia socio-politica de la emigración transoceánica en Galicia (1890-1930) in Estudios Migratorios Latinoamericanos, año 9, n." 27, págs. 301-346.

(1995): "¿Americanos revolucionarios ou indianos reformistas? Sobre os emigrantes a a Política na Galicia da restauración. (1919-1923)" in Anuario Brigantino, n.ำ 17, págs. 187-228.

Costa Rico, A. (1989): "As sociedades dos americanos e a educación en Galicia" in Revista da Comisión Galega do V Centenario, n.ํ⒌ A Coruña, págs. 89-140. 
tributaria local que la vieja élite turnista utilizaba como arma electoral. En la experiencia agraria, el labrego gallego toma conciencia del valor de los recursos políticos proactivos (votos, movilizaciones, boicot como táctica de negociación) y reactivos (las viejas violencias comunitarias contra personas y bienes) para desafiar a las élites que monopolizan la representación institucional de un estado oligárquico y proteccionista, contrario a sus intereses económicos de clase. La sintonia con las interpelaciones regionalistas de la clase media le convertirán en masa de maniobra electoral que certifique la inserción de empresarios políticos como Basilio Alvarez, Amado Garra o Pita Romero en la nueva élite de poder republicana tal como Hervés Sayar y Quintana Garrido han señalado.

Confiados en el diseño de un Turnismo en el que "el sufragio universal pudo ser una vergüenza, un escandaloso mercado repugnante, pero en realidad nunca ha sido un peligro" ${ }^{34}$, los notables dinásticos se alarmaron ante la movilización del campesinado para la acción colectiva por empresarios políticos procedentes de los sectores de clase media mejor formados política e intelectualmente, en las campañas de 1912-1914 y 19171923. Desde las organizaciones agrarias, nuestros labregos consiguieron un protagonismo en la relativa modernización de los espacios económicos y políticos que condicionaban su reproducción social a la par que se construian como ciudadanos con un imaginario colectivo propio. Procesos de articulación interrumpidos por la sublevación de julio del Treinta y Seis, conscientes quizás los sectores reaccionarios que apoyaron a los golpistas en Galicia del lampedusiano adagio de que "solamente los campesinos se desprecian a si mismos. Cuando aprendan a burlarse de los otros, el ciclo se cerrará y será necesario volver al comienzo".

34 La frase de Sagasta aparece citada in SANCHEZ MARRoro, F. (1979): Sindicalismo agrario y movimiento obrero. Cáceres, 1906-1920. Pág. 14. Del mismo autor cfr.:

(1993): "Los notables y el control politico, las elecciones parlamentarias en Extremadura durante la Restauración, 1876-1886" in Investigaciones Históricas, XIII. Valladolid, págs. 236-266.

(1994): "Violencia campesina, impotencia pequeño-burguesa y reacción conservadora. El Sexenio democrático en Extremadura» in Anales de Historia Contemporánea, 10. 